University of Nebraska - Lincoln

DigitalCommons@University of Nebraska - Lincoln

Peter Dowben Publications

Research Papers in Physics and Astronomy

2009

\title{
The surface core level shift for lithium at the surface of lithium borate
}

David Wooten

Air Force Institute of Technology, Wright Patterson Air Force Base, $\mathrm{OH}$

Ihor Ketsman

University of Nebraska-Lincoln, iketsman@gmail.com

Jie Xiao

University of Nebraska-Lincoln, jie.xiao@helmholtz-berlin.de

Yaroslav B. Losovyj

Louisiana State University at Baton Rouge, ylozovyy@indiana.edu

J. C. Petrosky

Air Force Institute of Technology, James.Petrosky@afit.edu

See next page for additional authors

Follow this and additional works at: https://digitalcommons.unl.edu/physicsdowben

Part of the Physics Commons

Wooten, David; Ketsman, Ihor; Xiao, Jie; Losovyj, Yaroslav B.; Petrosky, J. C.; McClory, J.; Burak, Ya. V.; Adamiv, V. T.; and Dowben, Peter A., "The surface core level shift for lithium at the surface of lithium borate" (2009). Peter Dowben Publications. 233.

https://digitalcommons.unl.edu/physicsdowben/233

This Article is brought to you for free and open access by the Research Papers in Physics and Astronomy at DigitalCommons@University of Nebraska - Lincoln. It has been accepted for inclusion in Peter Dowben Publications by an authorized administrator of DigitalCommons@University of Nebraska - Lincoln. 


\section{Authors}

David Wooten, Ihor Ketsman, Jie Xiao, Yaroslav B. Losovyj, J. C. Petrosky, J. McClory, Ya. V. Burak, V. T. Adamiv, and Peter A. Dowben 


\title{
The surface core level shift for lithium at the surface of lithium borate
}

\author{
David Wooten $^{\text {a }}$, I. Ketsman ${ }^{\text {b }}$, Jie Xiao ${ }^{\text {b }}$, Ya.B. Losovyj ${ }^{\text {b,c }}$, J. Petrosky ${ }^{\text {a }}$, J. McClory ${ }^{\text {a }}$, Ya.V. Burak ${ }^{\mathrm{d}}$, \\ V.T. Adamiv ${ }^{\mathrm{d}}$, P.A. Dowben ${ }^{\mathrm{b}, *}$ \\ a Air Force Institute of Technology, 2950 Hobson Way, Wright Patterson Air Force Base, OH 45433-7765, USA \\ ${ }^{\mathrm{b}}$ Department of Physics and Astronomy and the Nebraska Center for Materials and Nanoscience, University of Nebraska-Lincoln, P.0. Box 880111, Lincoln, NE 68588-0111, USA \\ c J. Bennett Johnston Sr. Center for Advanced Microstructures and Devices, Louisiana State University, 6980 Jefferson Highway, Baton Rouge, LA 70806, USA \\ ${ }^{\mathrm{d}}$ Institute of Physical Optics, Dragomanov 23, Lviv 79005, Ukraine
}

\section{A R T I C L E I N F O}

\section{Article history:}

Received 15 June 2009

Received in revised form

30 August 2009

Accepted 31 August 2009

PACS:

33.60.CV

68.35.Md

79.60. $-\mathrm{i}$

05.70.Np

68.47.Ch

Keywords:

Oxide dielectric layers

Lithium tetraborate

Surface-to-bulk core level shift

\begin{abstract}
A B S T R A C T
The shallow Li $1 \mathrm{~s}$ core level exhibits a surface-to-bulk core level shift for the stoichiometric $\mathrm{Li}_{2} \mathrm{~B}_{4} \mathrm{O}_{7}(110)$ surface. Angle-resolved photoemission spectroscopy was used to indentify Li $1 \mathrm{~s}$ bulk and surface core level components at binding energies $-56.5 \pm 0.4$ and $-53.7 \pm 0.5 \mathrm{eV}$, respectively. We find photoemission evidence for surface states of $\mathrm{Li}_{2} \mathrm{~B}_{4} \mathrm{O}_{7}(110)$ that exist in the gap of the projected bulk density of states. The existence of surface states is consistent with the large surface-to-bulk core level shift for the Li 1s core.
\end{abstract}

(c) 2009 Elsevier B.V. All rights reserved.

\section{Introduction}

The study of surface-to-bulk core level shifts has a long and rich history $[1,2]$ and, from the outset, has been given considerable theoretical support [3-7]. Application of the technique to alkalimetal-containing compounds, in particular dielectric compounds should yield very large surface-to-bulk core level binding energy shifts. Surface-to-bulk core level shifts have been observed for oxides [8], but with only a few examples that have incorporated the alkali metals, particularly lithium $[9,10]$. With alkali metals, the concept of multiple valence states cannot apply so that any observation of a surface-to-bulk core level shift would suggest the presence of a surface electronic structure far different from the bulk.

For oxides like the lithium borates, surface termination should lead to a very different oxygen coordination of the alkali metal, yet there are few, if any, reports of a surface-to-bulk core level shift for lithium in such oxide compounds [9] or even for the tungsten and

\footnotetext{
* Corresponding author. Tel.: +1402 472 9838; fax: +1 4024722879.

E-mail address: pdowben@unl.edu (P.A. Dowben).
}

molybdenum bronzes, the latter being quasi-one-dimensional materials based on lithium or alkali metal chains [10].

Obviously both polar and non-polar surfaces can exist at oxide compound surfaces, but polar surfaces tend to be less stable and more susceptible to surface reconstructions. The various possible oxide surface terminations should exhibit surface-to-bulk core level shifts, although the extent of the surface-to-bulk core level shift may vary widely. Surface reconstructions, as well as major surface lattice relaxations can complicate the observed surfaceto-bulk core level shift [1]. We have chosen to demonstrate the existence of a Li 1s surface-to-bulk core level shift for lithium tetraborate, $\mathrm{Li}_{2} \mathrm{~B}_{4} \mathrm{O}_{7}$ for the (110) orientation since the (110) surface termination is seen to have a largely non-polar surface termination $[11,12]$.

\section{Experimental}

The $\mathrm{Li}_{2} \mathrm{~B}_{4} \mathrm{O}_{7}$ single crystals were grown from the melt by the Czochralski technique as described elsewhere [13,14]. Clean surfaces were prepared by several methods, including heating and combinations of sputtering and subsequent annealing. The electronic structure and stoichiometry were similar in all cases. 
Angle-resolved photoemission spectra were obtained using plane polarized synchrotron light dispersed by a $3 \mathrm{~m}$ toroidal grating monochromator $[15,16]$, at the Center for Advanced Microstructures and Devices (CAMD) [17]. The measurements were made in an ultra-high vacuum (UHV) chamber employing a hemispherical electron analyzer with an angular acceptance of $\pm 1^{\circ}$, as described elsewhere $[15,16]$. The combined resolution of the electron energy analyzer and monochromator is $120-150 \mathrm{meV}$ for photon energies in the range $50-120 \mathrm{eV}$. The photoemission experiments were undertaken with a light incidence angle of $45^{\circ}$ with respect to the surface normal, unless stated otherwise. The photoelectrons were collected at emission angles as stated with respect to the surface normal throughout.

Temperature-dependent ultraviolet photoemission (UPS) was used to characterize the placement of the occupied states of $\mathrm{Li}_{2} \mathrm{~B}_{4} \mathrm{O}_{7}(100)$ and $\mathrm{Li}_{2} \mathrm{~B}_{4} \mathrm{O}_{7}(110)$ single crystals. Photoemission was conducted over a range of temperatures from 250 to $700 \mathrm{~K}$, but the data presented here were taken at $623 \mathrm{~K}$, where surface charging was found to be negligible. In order to differentiate between surface and bulk components of the Li 1s core, the photoelectron emission angle was varied, as has become the standard [1] and historical [2] practice. Surface charging shifts in the photoemission were accounted for using the $\mathrm{O} 2 \mathrm{~s}$ shallow quasi-core level and the valence band spectra taken as a function of temperature.

Even though this undoped-albeit with some nominal contribution from unfilled oxygen vacancies-crystal material is dielectric, the binding energies are reported relative to the Fermi level $\left(\mathrm{E}-\mathrm{E}_{\mathrm{F}}\right)$, with the Fermi level (chemical potential) placed within the gap. The location of the Fermi level was determined via angle-resolved photoemission using tantalum films in electrical contact with the samples. Using the Fermi level as the reference for the observed binding energies of the occupied and unoccupied states of $\mathrm{Li}_{2} \mathrm{~B}_{4} \mathrm{O}_{7}(110)$, as done here, differs from the sometimes common practice of assigning binding energies with respect to the valence band maximum for lithium borate [18]. Prior studies of lithium tetraborate also have assigned their binding energies with respect to the chemical potential or Fermi level [9]. We chose the latter convention for this investigation for ease of comparison.

The inverse photoemission spectra (IPES) were obtained by using variable energy electrons incident parallel to the surface normal while measuring the emitted photons at a fixed energy (9.7 eV) using a Geiger-Müller detector [19-22]. The instrumental linewidth is $\sim 400 \mathrm{meV}$, as described elsewhere [19-22].

\section{The Li 1s surface-to-bulk core level shift}

Through the use of angle-resolved photoemission spectra taken from $\mathrm{Li}_{2} \mathrm{~B}_{4} \mathrm{O}_{7}(110)$ with the in-plane component of $\underline{\boldsymbol{E}}$ oriented along [0 01 ] and at a photon energy of $95 \mathrm{eV}$, we have identified the Li 1s core level photoemission feature, as shown in Fig. 1. After corrections for photovoltaic charging (as discussed above and elsewhere [11]), we place the Li 1s shallow core level binding energies at $-56.7 \pm 0.4$ to $-56.5 \pm 0.4 \mathrm{eV}$ depending on the surface termination (crystal orientation). These values are largely dominated by the bulk Li $1 \mathrm{~s}$ core level binding energy contributions because of the normal photoelectron emission geometry. By increasing the electron emission angle, two components can be easily resolved for the $\mathrm{Li}_{2} \mathrm{~B}_{4} \mathrm{O}_{7}(110)$ surface at $-56.5 \pm 0.4$ and $-53.7 \pm 0.5 \mathrm{eV}$, as illustrated in Fig. 1 .

From prior studies of the surface-to-bulk core level shift [1,2], the reasonable expectation is to observe an increase in the intensity of the surface component of the core level with increase in emission angle. The intensity of the Li 1s core level component for the $\mathrm{Li}_{2} \mathrm{~B}_{4} \mathrm{O}_{7}(110)$ surface at smaller binding energy -53.7 $\pm 0.5 \mathrm{eV}$ is seen to increase with increase in emission angle, and thus we assign the Li 1s component at this binding energy as the

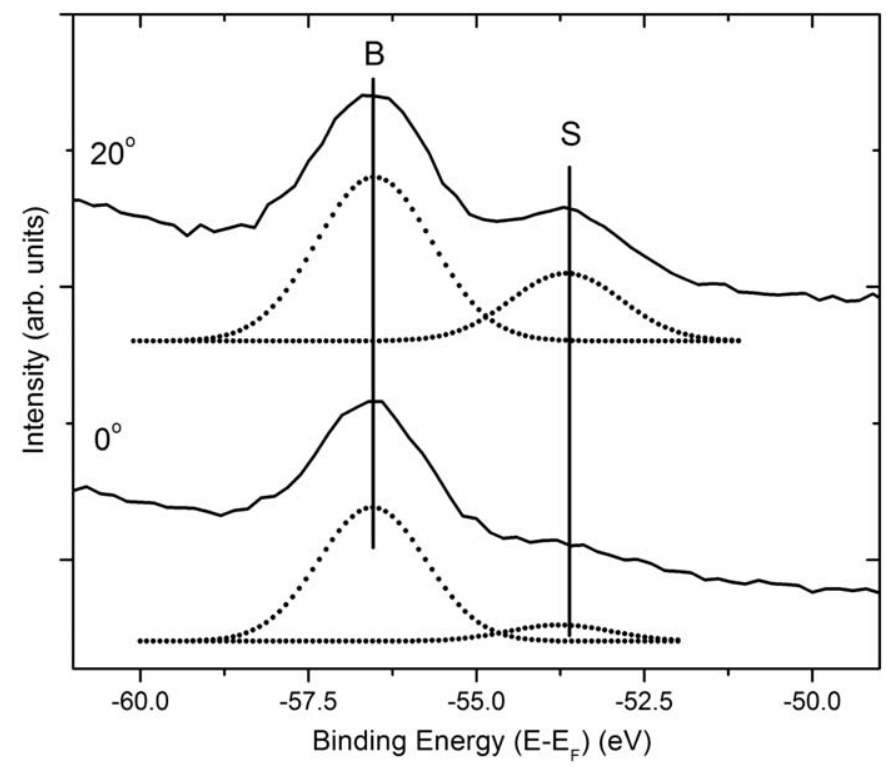

Fig. 1. Angle-resolved photoemission spectra of $\mathrm{Li}_{2} \mathrm{~B}_{4} \mathrm{O}_{7}(110)$ in the region of the Li $1 \mathrm{~s}$ core level, for photoelectron emission angles $20^{\circ}$ and $0^{\circ}$. In both cases, the inplane component of $\boldsymbol{E}$ was oriented along [0 01 ] with a light incidence angle $45^{\circ}$ and with photon energy $95 \mathrm{eV}$. The figure shows spectra with the instrumental background and secondary electron tail subtracted from the spectra with fittings to the Li 1s bulk and surface peaks, denoted B (bulk component contribution) and S (surface component contribution), respectively. The sample temperature for these measurements was $623 \pm 5 \mathrm{~K}$, to reduce surface charging.

surface component. The feature at a higher binding energy of $-56.5 \pm 0.4 \mathrm{eV}$ is attributed to the $\mathrm{Li} 1 \mathrm{~s}$ bulk component for $\mathrm{Li}_{2} \mathrm{~B}_{4} \mathrm{O}_{7}(110)$.

The binding energies for the bulk $\mathrm{Li} 1 \mathrm{~s}$ component $(-56.5 \pm 0.4 \mathrm{eV})$ tend to be somewhat higher in value than reported previously for lithium tetraborate $\left(\mathrm{Li}_{2} \mathrm{~B}_{4} \mathrm{O}_{7}\right)$ [9] at $-55.7 \mathrm{eV}$. Without adequate preparation of the stoichiometric clean surface, we have reason to believe that surface contributions (with a core level binding energy of $-53.7 \pm 0.5 \mathrm{eV}$ ) will dominate even the core level photoemission spectra. This leads to an artificial decrease in the core level binding energies that might otherwise be attributed solely to the bulk of lithium tetraborate and similar compounds. No surface component was reported [9] for the Li 1s core in that prior study.

We have deconvoluted the photoemission spectra in the region of the $\mathrm{Li} 1 \mathrm{~s}$ shallow core for both $0^{\circ}$ and $20^{\circ}$ photoelectron emission angles, as seen in Fig. 1. Any components other than those observed and attributed to the Li 1s surface-to-bulk core level shift do not appear to be significant, after the instrumental background spectra and secondary electron tail spectra have been subtracted, as indicated in Fig. 1. There is no additional component of the Li 1 shallow core level that provides a significant contribution to the photoemission in this binding energy region beyond those two component we can assign to the Li 1s surface and bulk core level components (Fig. 1).

The observed large binding energy separation between the surface and bulk components of the Li 1s core suggests the surface electronic structure of lithium tetraborate $\mathrm{Li}_{2} \mathrm{~B}_{4} \mathrm{O}_{7}(110)$ may differ significantly from the bulk.

\section{Evidence for a surface electronic structure distinct from the bulk}

Both $\mathrm{Li}_{2} \mathrm{~B}_{4} \mathrm{O}_{7}(100)$ and $\mathrm{Li}_{2} \mathrm{~B}_{4} \mathrm{O}_{7}(110)$ exhibit a density of states that qualitatively agrees with the results from model bulk band 
structure calculations for $\mathrm{Li}_{2} \mathrm{~B}_{4} \mathrm{O}_{7}[14,18]$, as seen in Fig. 2. While the valence band maximum is in reasonable agreement with prior investigations [9,18], yet within the angle-resolved photoemission, there is evidence for states within the valence band maximum to conduction band minimum gap (the insulator band gap), as seen in Fig. 3.

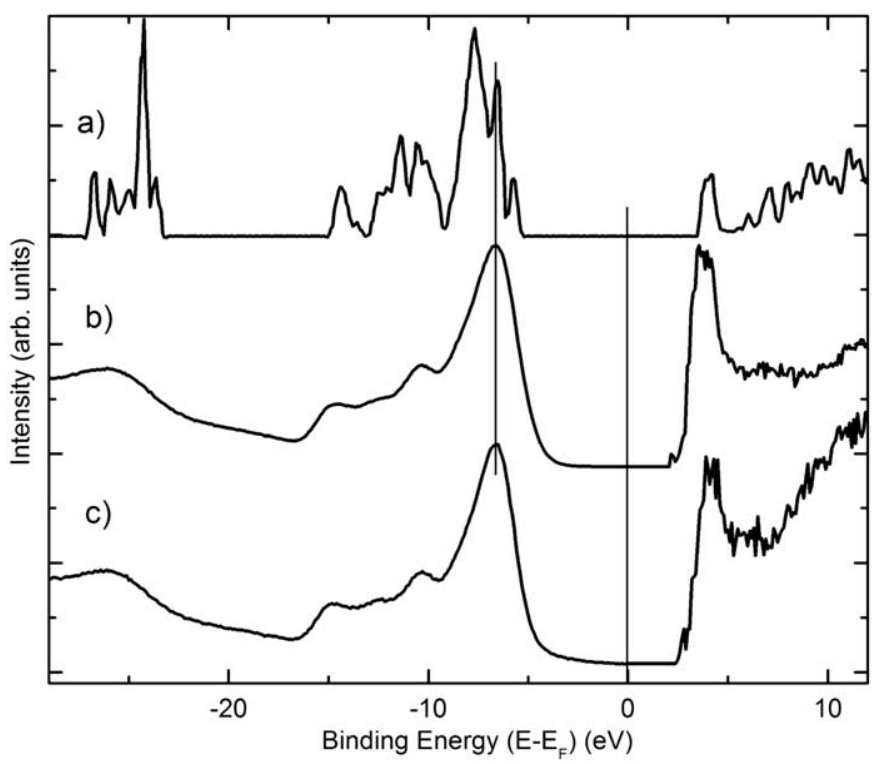

Fig. 2. The combined experimental photoemission and inverse photoemission results for bulk $\mathrm{Li}_{2} \mathrm{~B}_{4} \mathrm{O}_{7}$ compared with theory: (a) the theoretical density of states of solid $\mathrm{Li}_{2} \mathrm{~B}_{4} \mathrm{O}_{7}$ abstracted from the work of Islam et al. [18]; (b) combined experimental photoemission and inverse photoemission results for $\mathrm{Li}_{2} \mathrm{~B}_{4} \mathrm{O}_{7}(110)$ surface, taken with the in-plane $\boldsymbol{E}$ vector oriented along [1-10], and (c) $\mathrm{Li}_{2} \mathrm{~B}_{4} \mathrm{O}_{7}(100)$ surface, taken with the in-plane $\boldsymbol{E}$ vector oriented along [011]. The photoemission was taken at a photon energy of $56 \mathrm{eV}$ with electrons collected along the surface normal, while the inverse photoemission was taken with electrons incident normal to the sample.

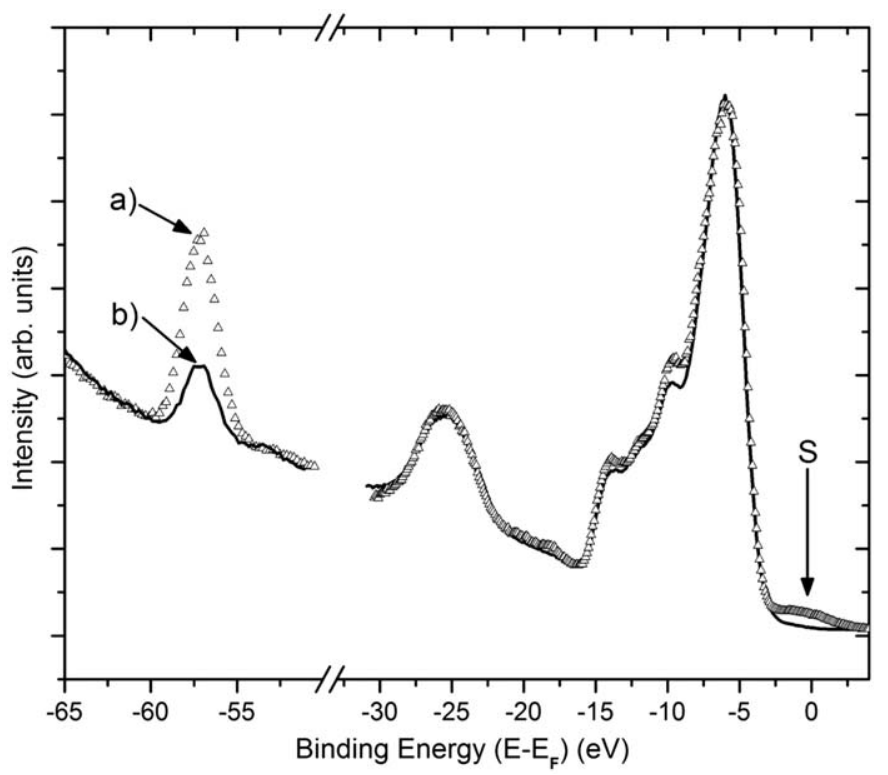

Fig. 3. Experimental light-polarization-dependent photoemission spectra for $\mathrm{Li}_{2} \mathrm{~B}_{4} \mathrm{O}_{7}$ (110) oriented along [001] with regards to the in-plane component of $\boldsymbol{E}$. The photon energy is $95 \mathrm{eV}$ with the photoelectrons collected along the surface normal; the light incidence angle was (a) $70^{\circ}\{\Delta \triangle \Delta\}$ or (b) $45^{\circ}\{-\}$ with respect to surface normal. The arrow indicates the position of the surface contribution (S) to the occupied density of states above the bulk density of states valence band maximum.
The light-polarization-dependent photoemission in the valence band region of the $\mathrm{Li}_{2} \mathrm{~B}_{4} \mathrm{O}_{7}(110)$ surface exhibits few differences between a light incidence angle of $70^{\circ}$, placing the electric vector $\underline{\boldsymbol{E}}$ more along the surface normal and a light incidence angle of $45^{\circ}$. The significant exception is the enhancement of the Li 1s core level in the photoemission spectra taken with a light incidence angle that places the electric vector $\underline{E}$ more along the surface normal. This enhancement of the Li $1 \mathrm{~s}$ would be expected for a state with a nearly pure s-like character, when the photoemission selection rule geometries favor even symmetry states. In these light-polarizationdependent photoemission spectra (Fig. 3), we do not observe the surface-to-bulk core level shift, as the surface component is weak due to the collection of the photoelectrons along the surface normal, i.e. as in the case of $0^{\circ}$ emission in Fig. 1.

This absence of differences in the light-polarization-dependent photoemission of the lithium tetraborate valence band region is consistent with the characterization of $\mathrm{Li}_{2} \mathrm{~B}_{4} \mathrm{O}_{7}(110)$ as a largely non-polar surface. Yet with a light incidence angle of $70^{\circ}$, there is a small density of state within the gap placed close to the Fermi level, as seen in Fig. 3. As these states fall into the gap of the projected bulk band structure (Fig. 2), we can initially conclude that these are in fact surface states. The observed intensity of these surface states are clearly affected by light polarization in photoemission and these states are likely of $\mathrm{s}$ or $\mathrm{p}_{\mathrm{z}}$ character given that they are enhanced with incident light where the electric vector $\underline{\boldsymbol{E}}$ is more along the surface normal.

We do not believe that these states, which are within the gap, are the result of surface defects. The states seen at binding energies in photoemission above the valence band maximum, close to the Fermi level, are seen for one incident light polarization but not the other (Fig. 3). This light-polarization-dependent photoemission spectroscopic result would be very unusual for a surface possessing surface defects. Furthermore, the same $\mathrm{Li}_{2} \mathrm{~B}_{4} \mathrm{O}_{7}(110)$ surface empty states have been later characterized, via inverse photoemission, as having a k-vector-dependent, strongly dispersing image potential state. Observation of such an image potential state would not be likely if the surface contained even a small number of surface defects. Image potential (Rydberg-like) states and their wave-vector-dependent dispersion are typically suppressed by surface defects [23].

\section{Summary}

For the $\mathrm{Li}_{2} \mathrm{~B}_{4} \mathrm{O}_{7}(110)$ surface, a very large surface-to-bulk core level shift of slightly less than $3 \mathrm{eV}$ has been observed for the Li 1s shallow core. The large Li 1s surface-to-bulk core level shift suggests that there is a surface electronic structure for $\mathrm{Li}_{2} \mathrm{~B}_{4} \mathrm{O}_{7}(110)$. This contention is supported by the valence band photoemission where we observe states within the band gap of the projected bulk density of states. These light-polarizationdependent photoemission states are observed to fall into the gap between the valence band maximum and conduction band minimum edges, in the region of the Fermi level. Consequently, these states seen in the light-polarization-dependent photoemission are consistent with surface states and indeed no other assignment appears possible. The correct assignment of the Li $1 \mathrm{~s}$ core level binding energies must, in the future, take into account the different binding energies of the surface and bulk contributions for lithium tetraborate and other related compounds.

\section{Acknowledgements}

This work was supported by the Defense Threat Reduction Agency (Grant nos. HDTRA1-07-1-0008 and BRBAA08-I-2-0128), and the Nebraska Research Initiative. This work was undertaken 
in partial fulfillment of the doctoral degree at AFIT by one author (DW). The views expressed in this article are those of the authors and do not reflect the official policy or position of the Air Force, Department of Defense or the US Government.

\section{References}

[1] D. Spanjaard, C. Guillot, M.C. Desjonquères, G. Tréglia, J. Lecante, Surf. Sci. Rep. 5 (1985) 1 .

[2] P.H. Cirtrin, G.K. Wertheim, Y. Baer, Phys. Rev. Lett. 41 (1978) 1425

[3] J.A. Appelbaum, D.R. Hamann, Solid State Commun. 27 (1978) 881.

[4] B. Johansson, N. Mårtensson, Phys. Rev. B 21 (1980) 4427.

[5] A. Rosengren, B. Johansson, Phys. Rev. B 22 (1980) 3706.

[6] P.J. Feibelman, J.A. Appelbaum, D.R. Hamann, Phys. Rev. B 20 (1979) 1433.

[7] P.J. Feibelman, D.R. Hamann, Solid State Commun. 31 (1979) 413.

[8] J. Zhang, P.A. Dowben, D. Li, M. Onellion, Surf. Sci. 329 (1995) 177.

[9] A. Yu Kuznetsov, A.V. Kruzhalov, I.N. Ogorodnikov, A.B. Sobolev, L.I. Isaenko, Phys. Solid State 41 (1999) 48.

[10] Kevin Smith, Boston University, private communication.

[11] D. Wooten, I. Ketsman, Jie. Xiao, Ya.B. Losovyj, J. Petrosky, J. McClory, Ya.V. Burak, V.T. Adamiv, P.A. Dowben, Mater. Res. Soc. Symp. Proc. 1164 (2009) 4.
[12] D. Wooten, I. Ketsman, J. Xiao, Ya.B. Losovyj, J. Petrosky, J. McClory, Ya.V. Burak, V.T. Adamiv, P.A. Dowben, in preparation.

[13] Ya.B. Burak, V.T. Adamiv, I.M. Teslyuk, V.M. Shevel, Radiat. Measure. 38 (2004) 681.

[14] V.T. Adamiv, Ya.V. Burak, I.V. Kityk, J. Kasperczyk, R. Smok, M. Czerwinski, Opt. Mater. 8 (1997) 207

[15] Y. Losovyj, I. Ketsman, E. Morikawa, Z. Wang, J. Tang, P. Dowben, Nucl Instrum. Methods Phys. Res. A 582 (2007) 264.

[16] P.A. Dowben, D. LaGraffe, M. Onellion, J. Phys. Cond. Matter 1 (1989) 6571.

[17] J. Hormes, J.D. Scott, V.P. Suller, Synchrotron Radiat. News 19 (2006) 27.

[18] M.M. Islam, V.V. Maslyuk, T. Bredow, C. Minot, J. Phys. Chem. B 109 (2005) 13597.

[19] J. Choi, P.A. Dowben, S. Ducharme, V.M. Fridkin, S.P. Palto, N. Petukhova S.G. Yudin, Phys. Lett. A 249 (1998) 505.

[20] J. Choi, C.N. Borca, P.A. Dowben, A. Bune, M. Poulsen, S. Pebley, S. Adenwalla S. Ducharme, L. Robertson, V.M. Fridkin, S.P. Palto, N. Petukhova, S.G. Yudin, Phys. Rev. B 61 (2000) 5760.

[21] J. Xiao, L.G. Rosa, M. Poulsen, D.Q. Feng, S. Reddy, J.M. Takacs, L. Cai, Jie. Zhang, S. Ducharme, P.A. Dowben, J. Phys. Condens. Matter 18 (2006) L155.

[22] D.N. Mcllroy, J. Zhang, P.A. Dowben, D. Heskett, Mater. Sci. Eng. A 217/218 (1996) 64

[23] N.V. Smith, Rept. Prog. Phys. 51 (1988) 1227. 